\title{
Investigating the Physiological Fit of Janitor, Safety Guard and Facility Workers with Their Jobs
}

\author{
Neda Mahdavi ${ }^{1}$ (D), Maryam Zarei², Negin Keshvari' ${ }^{1}$, Younes Mohammadi \\ Mahdi Zarei ${ }^{2}$, Rashid Heidarimoghadam ${ }^{1}$ iD
}

1. Department of Ergonomics, Occupational health and safety research center, School of Public Health, Hamadan University of Medical Sciences, Hamadan, Iran

2. Center of the excellence of occupational health, occupational health and safety research center, School of Public Health, Hamadan University of Medical Sciences, Hamadan, Iran

3. Modeling of noncommunicable diseases research center, Hamadan University of medical sciences, Hamadan, Iran4Department of occupational health engineering, Occupational health and safety research center, School of Public Health, Hamadan University of Medical Sciences, Hamadan, Iran

Article Info

Received: 2020/04/27;

Accepted: 2020/06/10;

ePublished: 2020/07/03

doi) 10.30699/jergon.8.1.42

Use your device to scan and read the article online

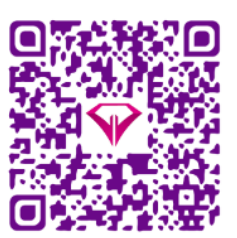

Corresponding Author Rashid Heidarimoghadam Department of Ergonomics, School of Public Health, Hamadan University of Medical Sciences, Hamadan, Iran Tel: 9181113692

Email:

Dr_Haidari@yahoo.com

\section{ABSTRACT}

Background and Objectives: One of the most important aspects of ergonomics is physiologic balance between human characteristics and their jobs. This study aimed to investigate the physiological characteristics of janitor, safety guard and facility workers of a work organization and determine their physiological fit.

Methods: A total of 70 staff were evaluated using Queen's college step test, N20 body composition analyzer, SECA scale, RS800CX Polar pacemaker. Descriptive statistics and analytical tests including ANOVA and Pearson correlation were used. The data was analyzed using SPSS 20.

Results: Body Mass Index (BMI) and fat percentage (Fat\%) of employees were beyond the optimal range, but Waist to Hip Ratio (WHR) were in the range. Also, the average Maximum Volume of Oxygen consumption $\left(\mathrm{VO}_{2 \max }\right)$ were $42 / 1 \pm 62 / 33$ $\mathrm{mL} / \mathrm{kg} / \mathrm{min}$ and the average of working capacity (maximum Physical Work Capacity: $\mathrm{PWC}_{\max }$ ) were $16 / 63 \pm 4 / 46 \mathrm{kcal} / \mathrm{min}$.

Conclusion: The results indicated that the level of some physical characteristics is inappropriate, physical fitness is poor and individual capabilities and job requirements are not in balance. Using standardized recruitment tests, providing the possibility of sports activities (by organizations) and finding integrated indicators that simultaneously take into account the physical, mental, social and environmental capabilities of individuals to determine work capacity (by researchers), can be facilitating steps to establish an ergonomic balance in the workplace.

Keywords: Physiological fit, $\mathrm{VO}_{2 \max }$, PWC, Body composition analysis

Copyright $\odot$ 2020, This is an original open-access article distributed under the terms of the Creative Commons Attribution-noncommercial 4.0 International License which permits copy and redistribute of the material just in noncommercial usages with proper citation.

How to Cite This Article:

Mahdavi N, Zareei M, Keshvari N, Mohamadi Y, Zareei M, Haidarimoghadam R. Investigating the Physiological Fit of Janitor, Safety Guard and Facility Workers with Their Jobs. Iran J Ergon. 2020; 8 (1) :42-55 
بررسى تناسب فيزيولوزيك كاركنان تأسيسات، خدمات و انتظامات با مشاغل آنها

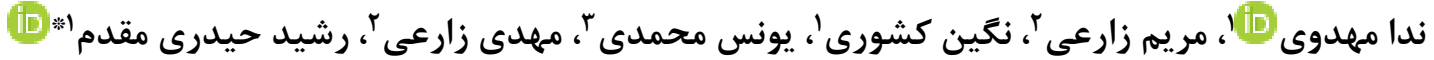

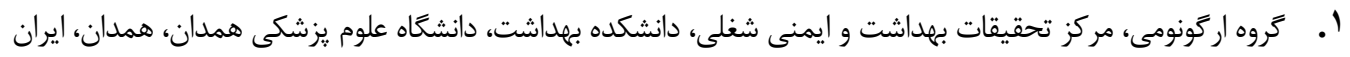

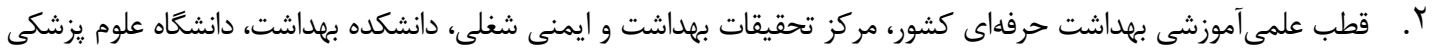

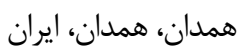

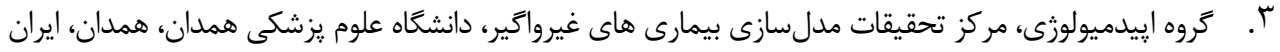

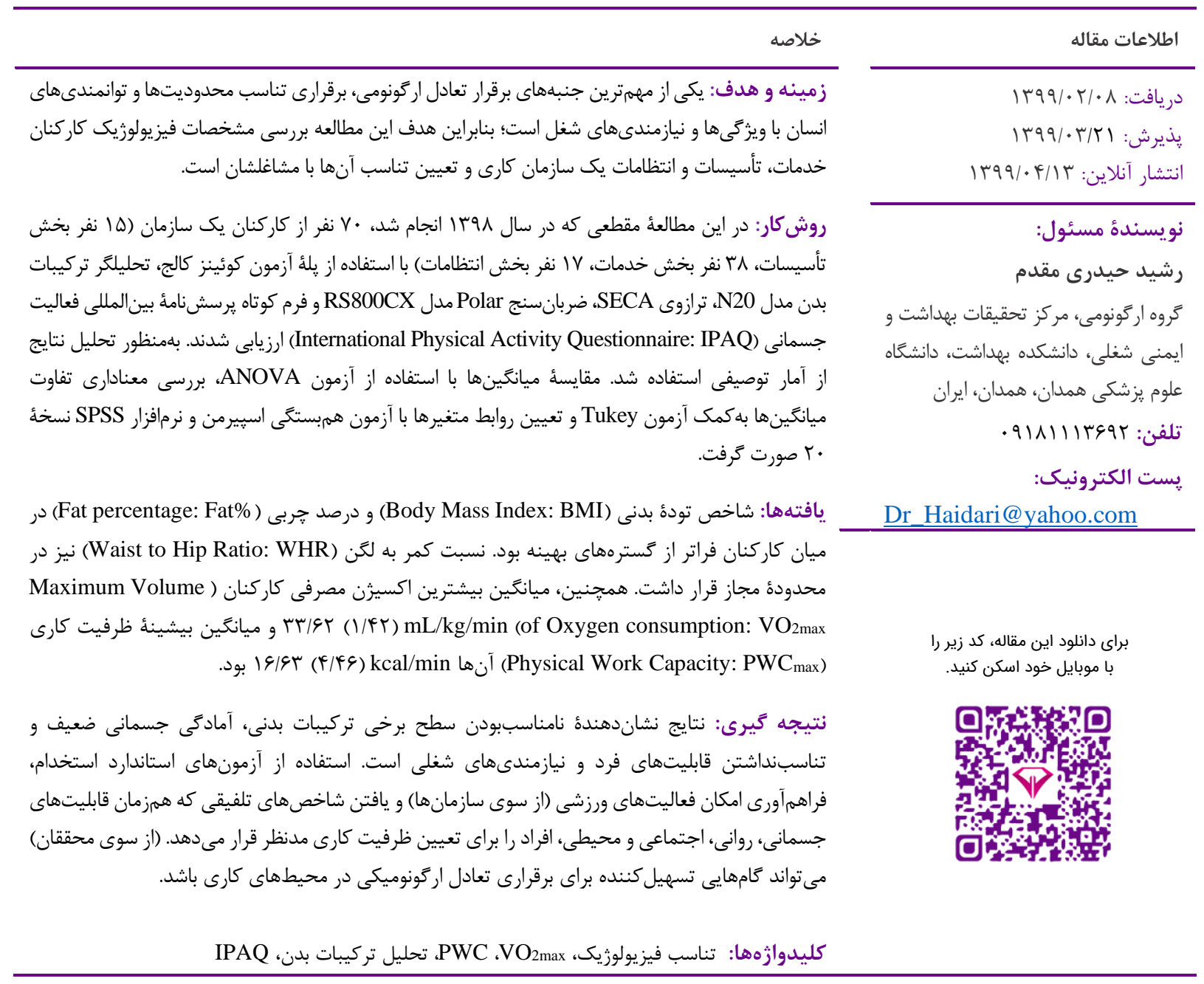

مقدمه

تفاوتهاى فيزيولوزيكى ميان افراد است [س]. تعادل فيزيولوزيك برقرارى تعادل ميان توانيىها و محدوديتهاى فيزيولوزيك كاركنان با نيازمندىهاى فيزيولوزيك وظايف شغلى آنهاست [F]. بامنظور حفظ سلامت جسمانى و روانى كاركنان، بايد باني تناسب منطقى بين نيازمندىهاى فيزيولوزيك كار (مانند ميزان انرزى موردنياز براى انجام كار) و مشخصات فيزيولوزيك كاركنان
برقرارى تعادل ميان توانيىها و محدوديتهاى فرد و

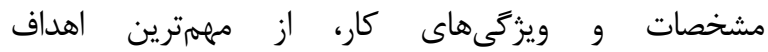
ارگتونوميستهاست [1]]. امروزه برقرارى تناسب آنترويومتريكى يعنى توجه به مشخصات آنترويومتريكى افراد و توجه به اين

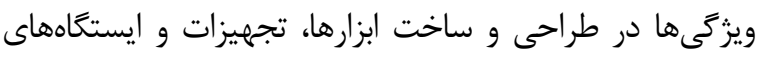

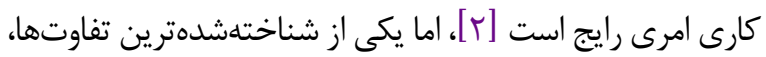




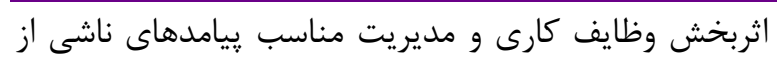

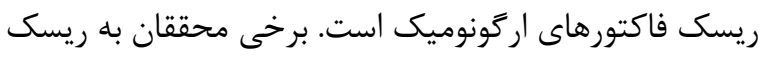

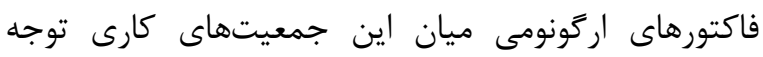

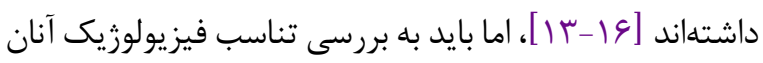

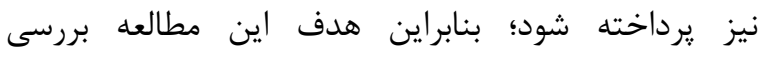
ويزگ هى هاى فيزيولوزيك كاركنان خدمات، حراست و و تأسيسات

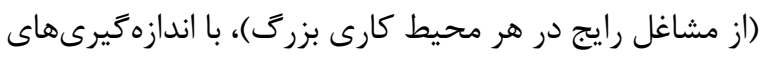

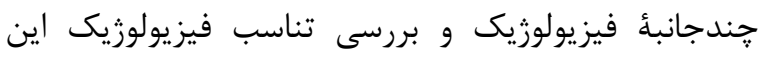

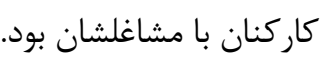

\section{روش كار}

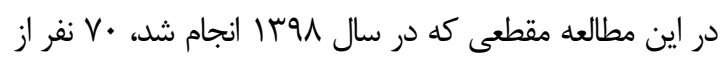

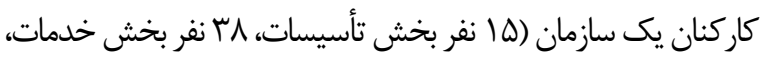

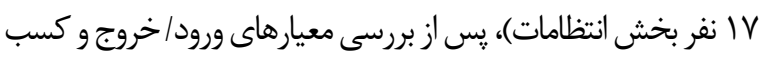

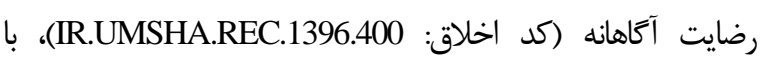

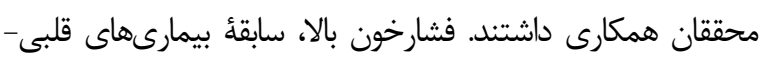

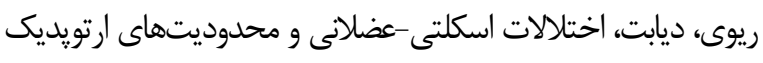

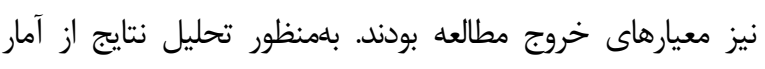

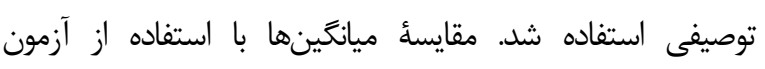

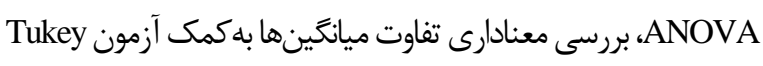

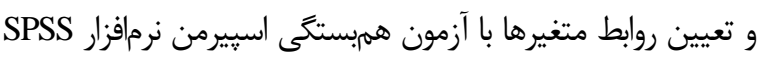

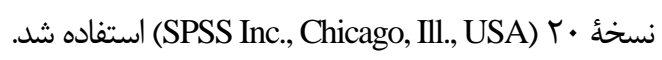
در مرحلة اول، اطلاعات دموكرافيك، جنسيت، تأهل، سن،

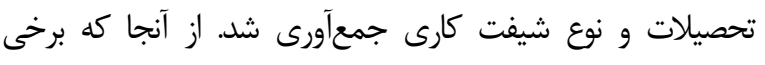

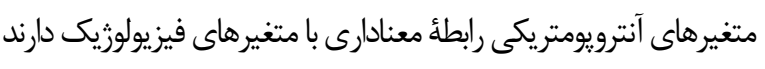

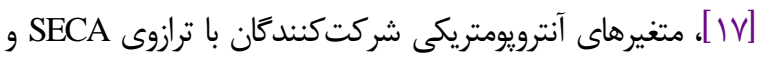

دستخاه تحليلكر تركيبات بدنى مدل N-20 تعيين شد (شكل () ).

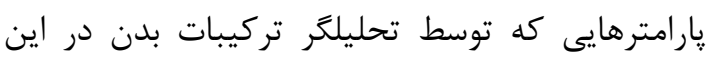

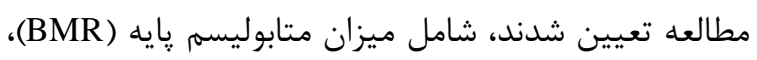

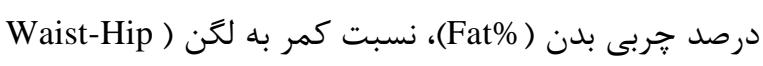

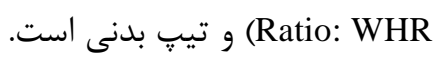

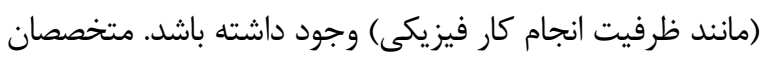

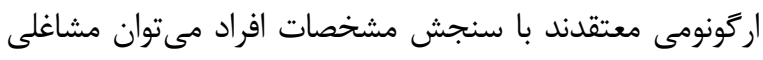

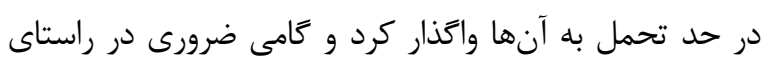

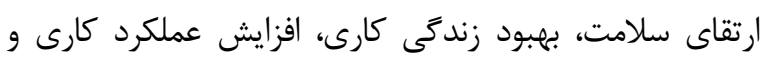
بهرهورى سازمانى برداشت [1 [1]

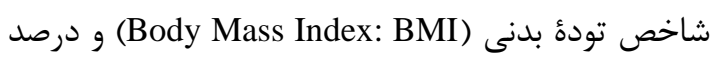

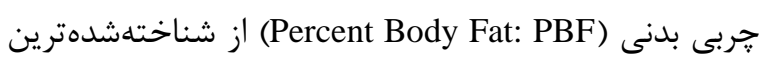

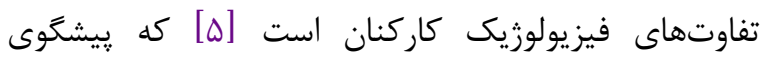

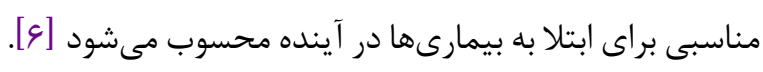

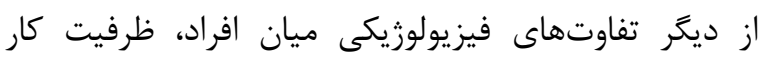

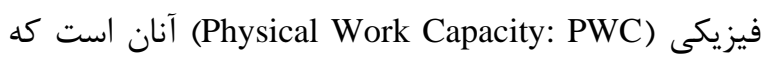
تناسب افراد با شغلشان را براساس حداكثر انرزى مصرفى آنها

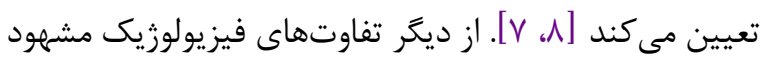
بين افراد مىتوان به تفاوت در ميزان بيشينأ اكسيرن مصرفى ني (Maximum Volume of Oxygen consumption: $\mathrm{VO}_{2 \max }$ ) يا ميزان ضربان قلب بيشينه (Heart Rate اشاره كرد [9]. بهجرئت مىتوان كفت تفان تفاوت انسانها در

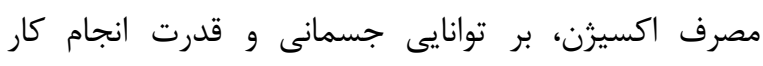

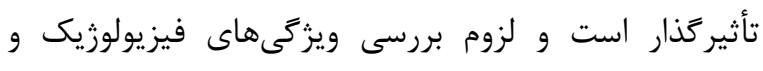

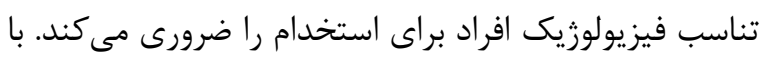

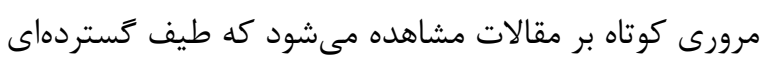

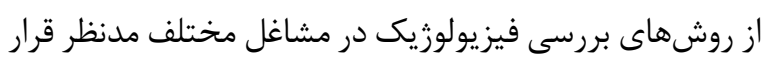

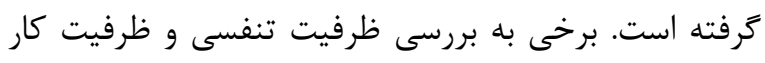

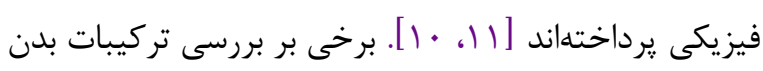

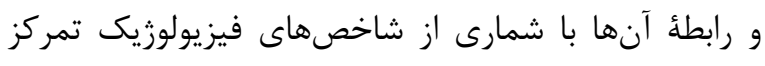

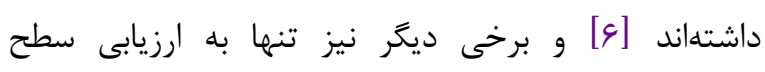
فعاليتهاى فيزيكى و ورزشى كاركنان توجه كردهاند [1 IT]

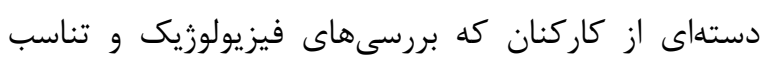

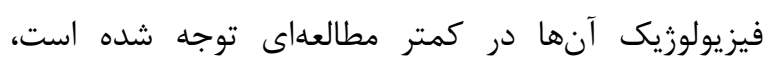
كاركنان تأسيسات، انتظامات و خدمات هستند.

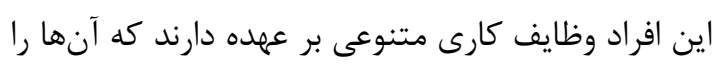

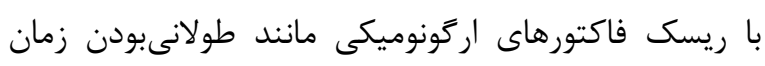

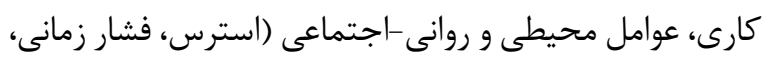

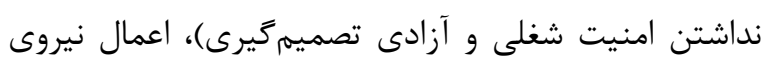

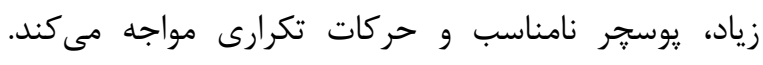

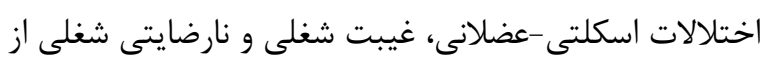

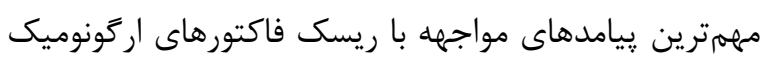

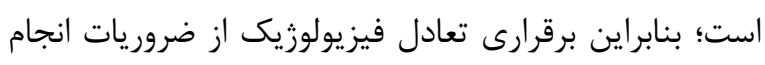




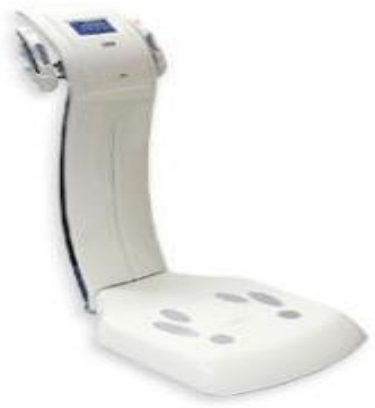

(B)

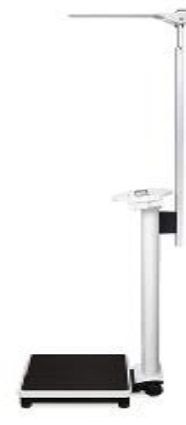

(A)

شكل I. (A) (A) ابزار سنجش قد و وزن SECA (B)

(B)

intra-class ) نيز روايى محتوايى و صورى و پايايى قابل قبولى دارد

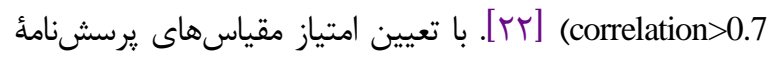
IPAQ

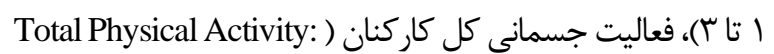
(PA برحسب MET) MET-min/week مصرف انرزى حين استراحت) تعيين شد. برحسب
در مرحلئ دوم كه با هدف تعيين سطح فعاليت جسمانى كاركنان صورت گرفت، از فرم كوتاه (Physical Activity: PA) يرسشنامة بينالمللى فعاليت بدنى (nternational Physical ) (Activity Questionnaire: IPAQ Fروههاى سنى ها تا و9 سال قابلاستفاده است و روايى و ريايايى

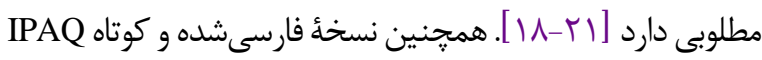

IPAQ "رابطهُ ا: نحوه محاسبه امتياز مقياس "يادهروى"

Walking MET-minutes/week = $3.3 \times$ walking minutes $\times$ "walking day"

$$
\text { رابطهُ r: نحوه محاسب امتياز مقياس 》فعاليت فيزيكى متوسط "IPAQ }
$$

Moderate MET-minutes/week = $4.0 \times$ moderate-intensity activity minutes $\times$ "moderate days"

$$
\text { رابطة سا: نحوهُ محاسبة امتياز مقياس "افعاليت فيزيكى شديد" }
$$

Vigorous MET-minutes/week $=8.0 \times$ vigorous-intensity activity minutes $\times$ vigorous "intensity days"

$$
\text { رابطءٔ f : نحوه محاسبة ميزان فعاليت جسمانى كل (Total Physical Activity) در يرسشنامه }
$$

Total Physical Activity: PA $_{\text {total }}=$ Walking MET-minutes/week + Moderate MET-minutes/week + Vigorous MET-minutes/week

از آزمون گِله) و PWC با يله قابلتنظيم (متناسب با ابعاد

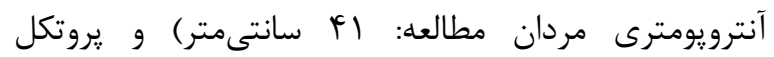

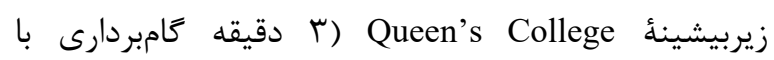
ضربآهنگ عף ضرب در دقيقه (حدود F ز Fام در دقيقه)) و ضربانسنج يولار مدل Polar Electro Oy, ) RS800CX Finland سيس با استفاده از رابطة ه ه (منتج از روش نرخدهى

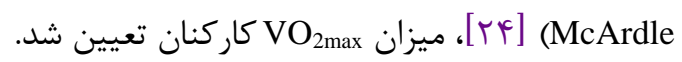

درنهايت اين يرسشنامه افراد را در سه دسته مختلف

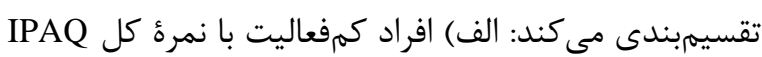
كمتر از MET-min/week • • • ب، ب) افراد داراى سطح فعاليت

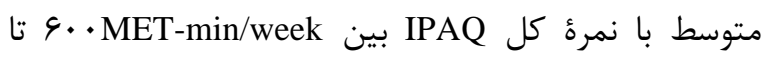

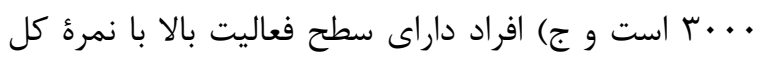

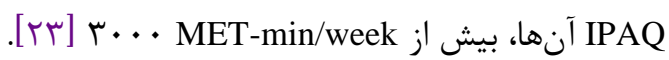
در مرحله سوم اين مطالعه، شاخصهاى فيزيولوزيكى

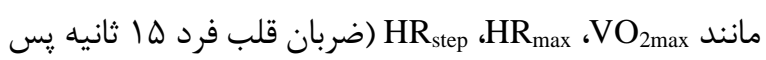




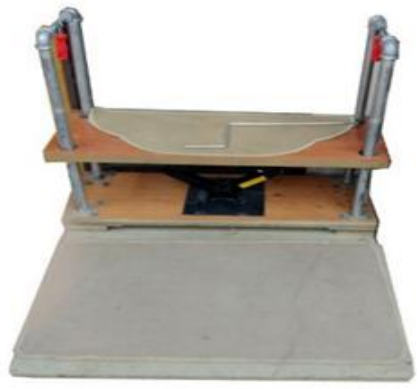

(D)

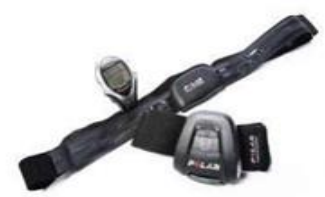

(C)

شكل r. يلئ آزمون كوئين (D) و ضربانسنج يولار (C)

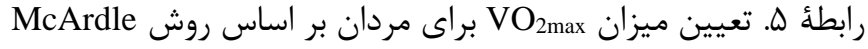
$\mathrm{VO}_{2 \max }(\mathrm{ml} / \mathrm{kg} / \mathrm{min})=111.33-0.42 \times$ Heart Rate $_{\text {max }}$ (beat per mimute)

\section{تجزيه و تحليلهاى آمارى}

آمار توصيفى دادهها با استفاده از آمارههاى ميانگين و انهاى انحراف معيار براى دادههاى كمى و فراوانى و درصد فراوانى براى دادههاى كيفى صورت گرفت. بلهنظور مقايسُٔ ميانخينها از آزمون ANOVA تعقيبى Tukey استفاده شد. همجنين بهمنظور تعيين روابط بين

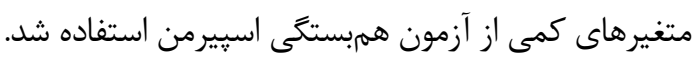

يافتهها

توصيف مشخصات دموگرافيك آزمودنىهاى يزوهش حاضر در جدول ا قابلمشاهده است. در جدول r، ميانگين و انحراف معيار تركيبات بدنى كاركنان و همبستگى اين متغيرها با ديخر تركيبات گنجانده شده است.
همجنين ميزان ظرفيت كارى مجاز براساس رابطهُ بينك

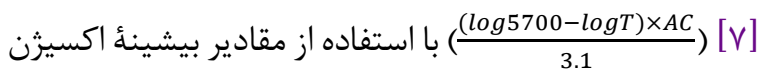
مصرفى برحسب كيلوكالرى در دقيقه (AC) و زمان كارى در هر شيفت برحسب دقيقه (T) تعيين شد. بدينترتيب ميزان ظرفيت كارى مجاز براى كاركنان خدمات با 1 ساعت كار در يك شيفت كارى حدود ها درصد ظرفيت بيشينهُ تنفسى آنها در نظر گرفته شد. علاوه بر اين در مشاغل تأسيسات و انتظامات بلهترتيب 9 ب و 19 درصد ظرفيت بيشينهُ تنفسى، بهعنوان ظرفيت كارى مجاز در نظر گرفته شد. مقادير ززارششده در جدول عا براساس اين ضرايب محاسبه شدهاند. در آخرين مرحله، اندازهخيرىهاى انجامشده با نورمهاى

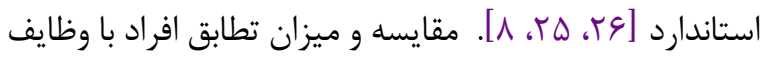
شغلىشان بررسى شد.

جدول ا. توصيف برخى مشخصات دموكر افيك كاركنان شركتكننده در مطالعه به تفكيك شغل

\begin{tabular}{|c|c|c|c|c|}
\hline انحراف معيار & ميانگين & تعداد & بخش هاى شغلى & متغير دموكر افيك \\
\hline$\Delta / \Delta \Lambda$ & r & r & خدمات & \multirow{4}{*}{ سن (year) } \\
\hline$\Delta / F \Delta$ & rr/FV & 10 & تأسيسات & \\
\hline V/AG & rN/fl & IV & انتظامات & \\
\hline$\varphi / \Delta \wedge \varphi$ & rF/F & $v \cdot$ & 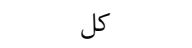 & \\
\hline $10 / 10$ & $V T / Y \Lambda$ & н & خدمات & \multirow{4}{*}{ وزن (kg) } \\
\hline$q / 4 q$ & VN/9T & 10 & تأسيسات & \\
\hline I./Ar & $V T / \cdot V$ & IV & انتظامات & \\
\hline $\mid r / \cdot$ & $V T / r$. & $v \cdot$ & كل & \\
\hline $9 / 19$ & IVD/FT & ऍ人 & خدمات & \multirow{4}{*}{ طول قامت (cm) } \\
\hline $\mathrm{V} / \mathrm{IV}$ & IVD/VT & 10 & تأسيسات & \\
\hline ع & IVF/DT & IV & انتظامات & \\
\hline G/VF & IVD/TV & v. & كل & \\
\hline
\end{tabular}




\begin{tabular}{|c|c|c|c|c|}
\hline انحراف معيار & ميانَين & تعداد & بخشهاى شغلى & متغير دموكرافيك \\
\hline Q/9T & $9 / \Delta \cdot$ & rی & 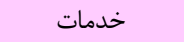 & \multirow{4}{*}{ سابقه كار (year/month) } \\
\hline$\Delta / 9 \Lambda$ & $\mid r / I T$ & 10 & ت تأسيسات & \\
\hline 9/9 & I9/V9 & IV & انتظامات & \\
\hline G/VF & $11 / \lambda r$ & V. & كل & \\
\hline
\end{tabular}

جدول r. ميانگين و انحر اف معيار تركيبات بدن مختلف در كاركنان و همبستكى معنادار آنها با ديگر تركيبات بدن

\begin{tabular}{|c|c|c|c|c|c|c|c|c|}
\hline \multicolumn{3}{|c|}{ همبستكى با ساير متغيرهاى مطالعه } & \multirow{2}{*}{ انحر اف } & \multirow[b]{2}{*}{ ميانَين } & \multirow{2}{*}{ انحراف } & \multirow[b]{2}{*}{ ميانكين } & \multirow{2}{*}{ شغلى بهاى } & \multirow[b]{2}{*}{ 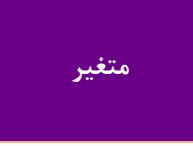 } \\
\hline sig & ضمربستخى & متغير & & & & & & \\
\hline$<+\mid \cdot+1$ & .191 & BMR & \multirow{7}{*}{$r / F 1$} & \multirow{7}{*}{$r r / G V$} & $\mathrm{r} / 9 \Lambda$ & $r r / F$. & خدمات & \multirow{7}{*}{ شاخص تودهُ بدن } \\
\hline$<\cdot 1 \cdot \bullet 1$ & $\cdot|f|$ & WHR & & & \multirow{5}{*}{$r / \Delta \varphi$} & \multirow{5}{*}{$r F / F \wedge$} & \multirow{5}{*}{ تأسيسات } & \\
\hline$\bullet /+\Delta$ & $\cdot / r F$ & Fat $\%$ & & & & & & \\
\hline$<+1 \cdot+1$ & 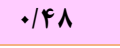 & 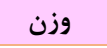 & & & & & & \\
\hline$\cdot / r_{*}$ & $\cdot / r v$ & جربى & & & & & & \\
\hline \multirow{2}{*}{$<\cdot / \cdot \bullet 1$} & \multirow{2}{*}{$\cdot / 4 q$} & 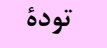 & & & & & & \\
\hline & & 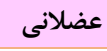 & & & $r / \Delta \mid$ & rr/Dr & انتظامات & \\
\hline$<+1 \cdot+1$ & $\cdot / \Delta \Lambda$ & 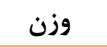 & \multirow{4}{*}{$r \cdot \varphi / r \Lambda$} & \multirow{4}{*}{$19 \Delta \cdot / F V$} & \multirow{2}{*}{$r r q / 9 \Delta$} & \multirow{2}{*}{$1949 / 9}$. & \multirow{2}{*}{ خدمات } & \multirow{4}{*}{ 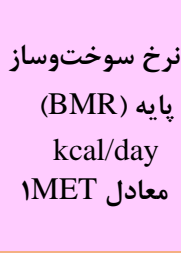 } \\
\hline $.1 \cdot 11$ &.$/ 49$ & WHR & & & & & & \\
\hline$<+1 \cdot+1$ & $\cdot / \Delta \Delta$ & عضلانى & & & $109 / 99$ & $\mid \& V \& / F$. & تأسيسات & \\
\hline$<+1 \cdot+1$ &. $\mid 91$ & BMI & & & IVE/VE & 194.190 & انتظامات & \\
\hline$<+1 .+1$ & $\cdot / \Delta \Lambda$ & Fat $\%$ & \multirow{5}{*}{$\cdot 1 \cdot V$} & \multirow{5}{*}{$\cdot / \wedge 9$} &.$/ V r$ & $\cdot / \wedge \Delta$ & 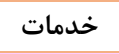 & \multirow{5}{*}{ كمر (WHR) كنَ به } \\
\hline$<+1 .+1$ & $\cdot|4|$ & BMI & & & \multirow{3}{*}{$\cdot / V q$} & \multirow{3}{*}{$\cdot / \Lambda \vee$} & \multirow{3}{*}{ تأسيسات } & \\
\hline$<+1 \cdot \bullet 1$ &.$/ 91$ & جربى & & & & & & \\
\hline $.1 \cdot 11$ & $\cdot / 49$ & BMR & & & & & & \\
\hline$<+1 .+1$ &.$/ \Delta \Delta$ & عضلانى & & & $\cdot / F T$ & $\cdot / \Lambda V$ & انتظامات & \\
\hline \multirow{3}{*}{$<+1 .+1$} & \multirow{3}{*}{$\cdot / \Delta \Lambda$} & \multirow{3}{*}{ WHR } & \multirow{3}{*}{$9 / 9 \mathrm{~V}$} & \multirow{3}{*}{$19 / F \Delta$} & V/A & $\| \wedge / \wedge \Delta$ & خدمات & \multirow{3}{*}{$\begin{array}{c}\text { درصد خربى بدن } \\
\text { (Fat } 1 .)\end{array}$} \\
\hline & & & & & $\Delta / \cdot 9$ & $r \cdot / v q$ & تأسيسات & \\
\hline & & & & & $F / \Delta q$ & $19 / V r$ & انتظامات & \\
\hline
\end{tabular}

Y ب Fat\% بين كاركنان انتظامات و خدمات تفاوت

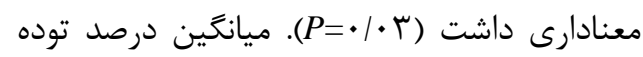
קربى بدنى كاركنان خدمات بهطور معنادار بيشتر از كاركنان انتظامات بود.

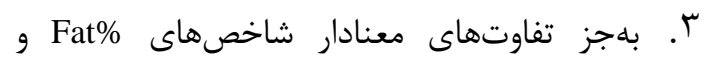
BMI با تركيب بدنى بين سه دسته از كاركنان مشاهده نشد.

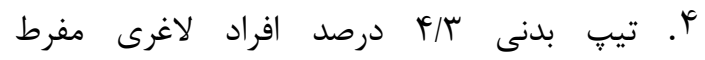
(Emaciation) كم (low fat muscle)، Fr/9 درصد افراد نرمال
نتايج بررسى تركيبات بدنى (با استفاده از دستگاه تحليل حدود \& أ درصد از كاركنان كمتر از كستره بهينه (كمتر از \|)،

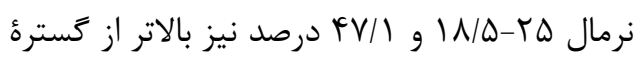
نرمال قرار گرفته بود. همجنين تفاوت اين شاخص تنها بين كاركنان خدمات و تأسيسات معنادار بود تأس تأسيسات بلهور معنادارى بيشتر از كاركنان

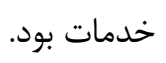


ندا مهدوى و همكاران | بررسى تناسب فيزيولوزيك كاركنان تأسيسات، خدمات و انتظامات با مشاغل آنها

(Standard weight)

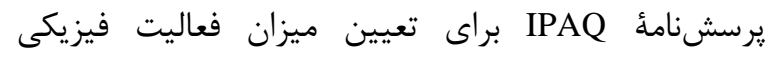

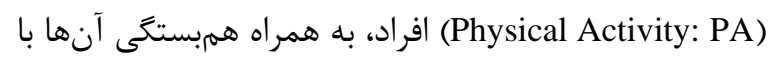
ديغر متغيرهاى مطالعه قابلمشاهده است.
داراى اضافهوزن (Fatty Over Weight) و 1N/9)

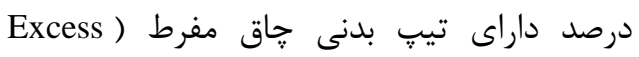
(Adiposity

جدول س. ميزان فعاليت فيزيكى برحسب MET-min/week در بين كاركنان

\begin{tabular}{|c|c|c|c|c|c|c|c|c|}
\hline \multicolumn{3}{|c|}{ همبستگى با ساير متغير هاى مطالعه } & \multirow{2}{*}{ انحراف } & \multirow{2}{*}{ ميانكين } & \multirow{2}{*}{ انحراف } & \multirow{2}{*}{ ميانگين } & \multirow{2}{*}{ شخىهاى شغلى } & \multirow{2}{*}{ مقياس } \\
\hline sig & ضريب همبستخى & متغير & & & & & & \\
\hline$\cdot 1 \cdot r$ & - - & تودهُ جربى & \multirow{3}{*}{$r V \Delta T / \Delta q$} & \multirow{3}{*}{ FTNT/Tr } & r.V/Ar & $4991 / 90$ & خدمات & \multirow{3}{*}{$\begin{array}{c}\text { فعاليت مربوط به } \\
\text { MET-) } \\
\text { (min/week }\end{array}$} \\
\hline$\cdot 1 \cdot \Delta \varphi$ & س & سابقه كار & & & พ^१৫/^६ & fq६q/AV & تأسيسات & \\
\hline$\cdot 1 \cdot \Delta \Lambda$ & س & WHR & & & $\varphi \cdot \wedge / q$. & $r q .91 . q$ & انتظامات & \\
\hline$\cdot 1 \cdot v V$ & - & FAT $\%$ & \multirow{5}{*}{ TVTH/VD } & \multirow{5}{*}{$r$ rqq/Fr } & $r \Delta 110$ & r س & $-1 \quad$. & \multirow{5}{*}{$\begin{array}{c}\text { فعاليت متوسط } \\
\text { MET-) } \\
\text { (min/week }\end{array}$} \\
\hline$\cdot 1 \cdot \Delta 9$ & מצ/•- & $\mathrm{PWC}_{\max }$ & & & $1 \cdot 01 / 17$ & $1.10 / v>$ & حدمات & \\
\hline$\cdot 1 \cdot 09$ & 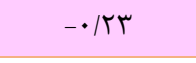 & $\mathrm{VO}_{2 \max }$ & & & meVh/. & r I & تأسسيات & \\
\hline $.1 \cdot 09$ & س & $\mathrm{HR}_{\text {step }}$ & & & & & & \\
\hline \multirow[t]{4}{*}{$\cdot / r V \cdot$} & $\cdot / T \Delta$ & عضودة & & & $r T \Delta \Delta / V T$ & TrTd/rq & انتظامات & \\
\hline & \multirow{3}{*}{--} & & \multirow{3}{*}{ ISVT/VT } & \multirow{3}{*}{ MIS/T } & $\mid \wedge \Delta \wedge / 9 \Lambda$ & $|f| N / 9 \Delta$ & خدمات & \multirow{3}{*}{$\begin{array}{c}\text { فعاليت سنَين } \\
\text { MET-) } \\
\text { (min/week }\end{array}$} \\
\hline & & & & & $10 G Y / q F$ & $|\Lambda \cdot \Lambda| \cdots$ & تأسيسات & \\
\hline & & & & & $\Delta \Delta q / \mathcal{F} \Delta$ & $r T \Delta / \Lambda \Lambda$ & انتظامات & \\
\hline $.1 \cdot 1 \mathrm{~V}$ & $\cdot 1 / 99$ & 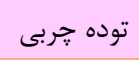 & \multirow{4}{*}{ DTYT/TI } & \multirow{4}{*}{$\Lambda \cdot r F / V q$} & FVVD/qT & $\Lambda \Delta F \cdot \mid q T$ & خدمات & \multirow{4}{*}{$\begin{array}{c}\text { فعاليت بدنى فرد يا } \\
\text { PAtotal } \\
\text { MET-) } \\
\text { (min/week }\end{array}$} \\
\hline$\cdot 1 \cdot \mathrm{rQ}$ & $-\cdot / T V$ & $\mathrm{VO}_{2 \max }$ & & & $\Delta \Delta \Delta \Delta / r V$ & 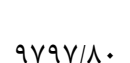 & تأسيسيات & \\
\hline$\cdot 1 \cdot r \Delta$ & $\cdot / 4 V$ & $\mathrm{HR}_{\text {step }}$ & & & & & & \\
\hline $.1 \cdot r \Delta$ & $-\cdot / T V$ & $\mathrm{PWC}_{\max }$ & & & DTGY/TV & $\Delta \cdot \wedge r / \Lambda$ & انتظامات & \\
\hline
\end{tabular}

PA

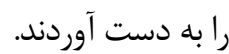

r. ميانكَين "اميزان فعاليت سنكينه كاركنان انتظامات

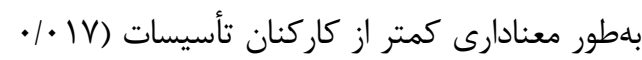
(P= شاخص تفاوت معنادارى در بين كاركنان خدمات و تأسيسات نداشت. "اميزان فعاليت ييادرورى" در بين كاركنان انتظامات

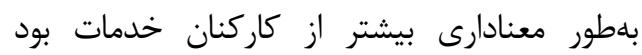
年)

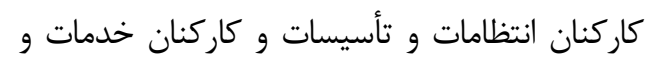

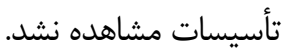
ه. اهيزان فعاليت متوسط افراد در سه كروه شغلى تفاوت معنادارى با يكديكر نداشت.
نتايج تكميلى بررسى PA افراد با استفاده از يرسشنامة

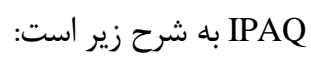

1. (9. MET-min/week افرادى با PA

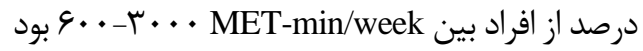

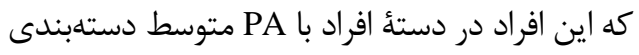

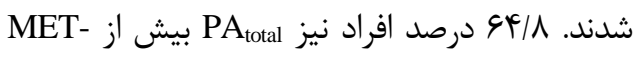


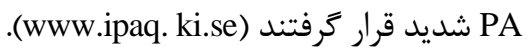

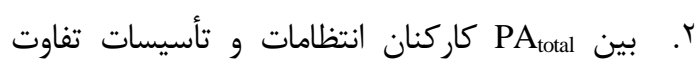

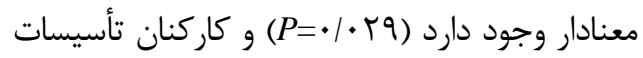
بلطور معنادارى فعاليت جسمانى بيشترى دارند. 


\begin{tabular}{|c|c|c|c|c|c|c|c|c|}
\hline \multirow{2}{*}{\multicolumn{3}{|c|}{ 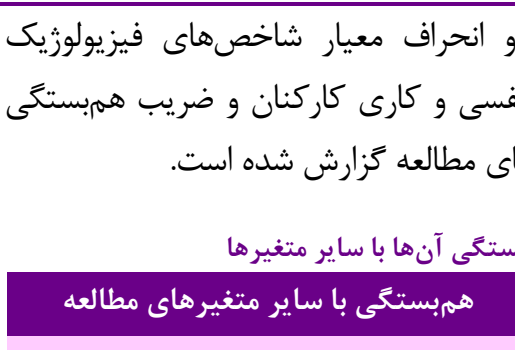 }} & ساير متغير & مرتبط: & \multicolumn{4}{|c|}{ 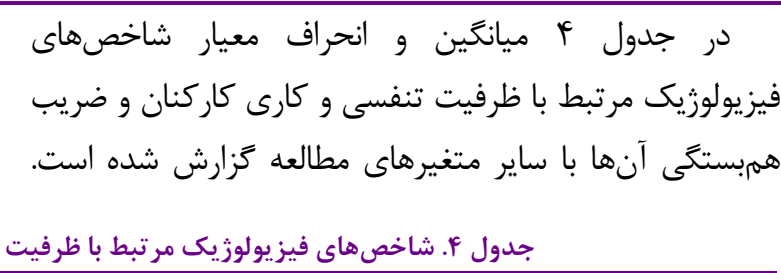 } \\
\hline & & & & & & & & \\
\hline sig & ضمريبت & متغير & انحراف & كل ميانين افراد & انحراف & ميانگين & 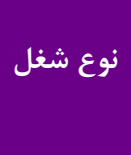 & شاخصهاى فيزيولوزيك \\
\hline \multirow{2}{*}{$<\cdot / \cdot \cdot 1$} & \multirow{2}{*}{-1} & \multirow[b]{2}{*}{ سن } & \multirow{3}{*}{$9 / 09$} & \multirow{3}{*}{$\mid \wedge \Delta / \Delta V$} & $\Delta / V V$ & $1148 / 9 \vee$ & خدمات & \multirow{3}{*}{$\begin{array}{c}\text { ضربان بيشينأ قلب } \\
\left(\mathrm{HR}_{\max }\right) \\
\text { (beat / min) }\end{array}$} \\
\hline & & & & & $\Delta / F \Delta$ & $\mid \wedge \& / \Delta T$ & تأسيسات & \\
\hline$\cdot / \cdot r$ & $-\cdot / V T$ & سابقه كار & & & V/A & $111 / 09$ & انتظامات & \\
\hline$<\cdot / \cdot \cdot 1$ & $-\cdot / r \Delta$ & 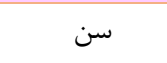 & \multirow{5}{*}{$19 / 9$} & \multirow{5}{*}{$1 \Delta \Delta / 9 V$} & r & & & \multirow{5}{*}{ 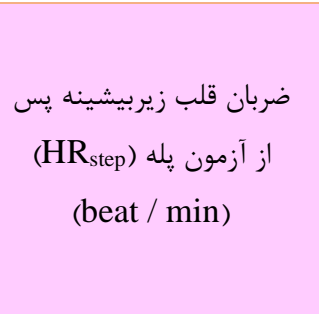 } \\
\hline $.1 . .4$ & ( & Fat $\%$ & & & $11 / \wedge \omega$ & 1011. & حدمات & \\
\hline$\cdot 1 \cdot 1$ & $\cdot / \mu$ & BMR & & & $11 / \Delta V$ & $|\Delta \Lambda / \psi|$ & تأسسات & \\
\hline$<\cdot \mid \cdot \cdot 1$ & $\cdot 10$ & WHR & & & & & & \\
\hline$<\cdot 1 \cdot \cdot 1$ & $\cdot 199$ & توده عضلانى & & & IT/QT & $109 / 91$ & انتظامات & \\
\hline \multirow{3}{*}{$<\cdot \mid \cdot \cdot 1$} & \multirow{3}{*}{. /4rq } & \multirow{3}{*}{ Fat $\%$} & \multirow{3}{*}{$1 / F T$} & \multirow{3}{*}{ 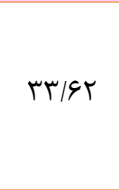 } & l/9T & $r T / \Lambda \cdot$ & خدمات & \multirow{3}{*}{$\begin{array}{c}\text { بيشترين حجم اكسيرن } \\
\text { مصرفى (VO } \\
\text { mL/(kg/min) }\end{array}$} \\
\hline & & & & & $1 / \pi \Delta$ & $r r / 9 q$ & 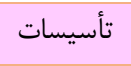 & \\
\hline & & & & & $1 / \Gamma \wedge$ & $r \Delta / \cdot \varphi$ & انتظامات & \\
\hline \multirow{6}{*}{$<\cdot / \cdot \cdot 1$} & \multirow{3}{*}{$\cdot / F F$} & \multirow{3}{*}{ Fat $\%$} & \multirow{3}{*}{$\cdot / \wedge \vee$} & \multirow{3}{*}{ 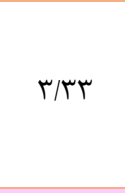 } & $1 / \cdot \Delta$ & $r / 4$. & خدمات & \multirow{3}{*}{$\begin{array}{c}\text { بيشينأ اكسيرن مصرفى } \\
\left(\mathrm{VO}_{2 \max }\right) \\
\mathrm{L} / \mathrm{min}\end{array}$} \\
\hline & & & & & .194 & $T / \Delta F$ & 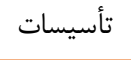 & \\
\hline & & & & & .199 & $r / \cdot \uparrow$ & انتظامات & \\
\hline & \multirow{3}{*}{ (مانند PWC) } & & \multirow{3}{*}{ 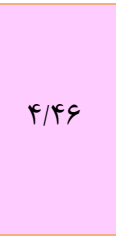 } & \multirow{3}{*}{$19 / 94$} & $\Delta / r \Lambda$ & IV & خدمات & \multirow{3}{*}{$\begin{array}{c}\text { ظرفيت كارى بيشينه } \\
(\mathrm{PWC} \text { max }) \\
\mathrm{VO}_{2 \max }(\mathrm{L} / \mathrm{min}) \times 5 \\
(\mathrm{Kcal} / \mathrm{min})\end{array}$} \\
\hline & & & & & r/l & IV/VT & تأسيسات & \\
\hline & & & & & $4 / 91$ & $I D / T Y$ & انتظامات & \\
\hline$\cdot 1 \cdot 19$ & $\cdot / 4 q$ & BMR & \multirow{11}{*}{$1 / \Lambda 1$} & \multirow{11}{*}{$\Delta / \cdot V$} & & & & \\
\hline.$/ \cdots 1$ &.$/ 015$ & WHR & & & $1 / \wedge \Delta$ & $\Delta / 9 \Delta$ & خدمات & \\
\hline$<\cdot \mid \cdot \cdot 1$ & $\cdot 19 V$ & توده عضلانى & & & & & & \\
\hline$\cdot / \cdot r$. & .109 & 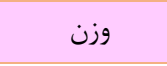 & & & & & & \\
\hline$\cdot / \cdot r$ & $\cdot / V \Delta$ & توده عضلانى & & &.$/ 9$. & $\Delta / / F$ & تأسيسات & ظرفيت كارى مجاز \\
\hline$\cdot 1 \cdot r q$ & $\cdot \mid \Delta \Lambda$ & WHR & & & & & & (PWC) \\
\hline$\cdot / \cdot r$ & $-\cdot / V$ & سن & & & & & & (Kcal / min) \\
\hline.$/ \cdot 1 r$ & .194 & Fat $\%$ & & & & & & \\
\hline$\cdot 1 \cdot \cdot 1$ & $\cdot / V V$ & توده عضلانى & & & .19. & $r / \cdot F$ & انتظامات & \\
\hline $.1 \cdot 1 \mathrm{f}$ & $\cdot 19$ & WHR & & & & & & \\
\hline$\cdot / \cdot r \Lambda$ & $-\cdot|0|$ & سابقه كار & & & & & & \\
\hline
\end{tabular}


ندا مهدوى و همكاران | بررسى تناسب فيزيولوزيك كاركنان تأسيسات، خدمات و انتظامات با مشاغل آنها

( $)$ و توجه به گسترئ سنى آنان

(تأسيسات:

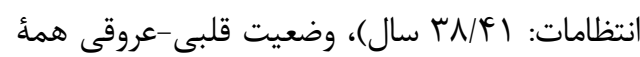

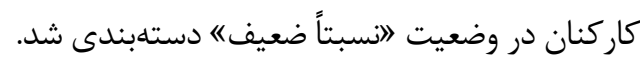

r r براساس سيستم كدبندى فعاليتهاى فيزيكى

[V، ، (Compendium of Physical Activities)

تفاضل ميزان انرزى استاندارد موردنياز (برحسب

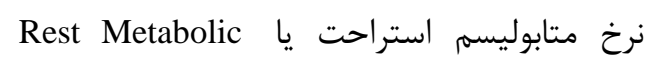
مate: RMR

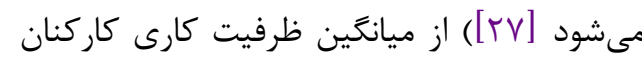

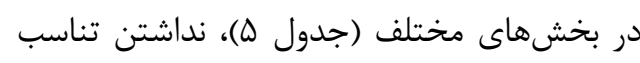

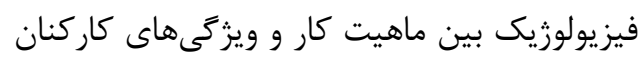

مشاغل خدمات و انتظامات مشاهده مىشود.

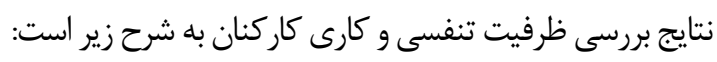

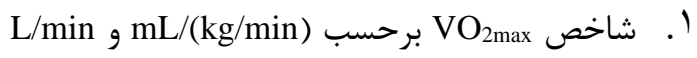

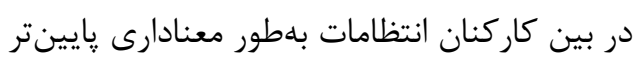

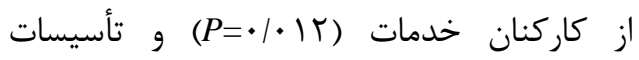

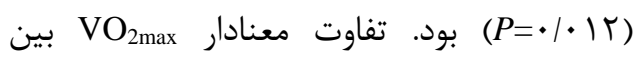
كاركنان خدمات و تأسيسات ديده نشد. r ب. بررسى آمارى هيج تفاوت معنادارى در

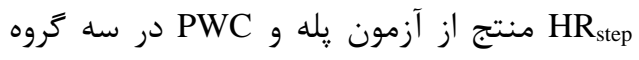

$$
\text { شغلى نشان نمى دهد. }
$$

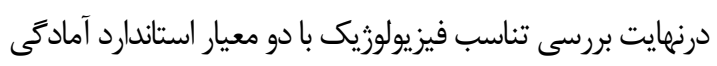

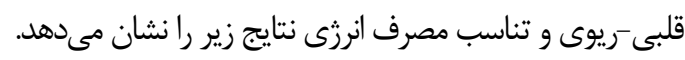

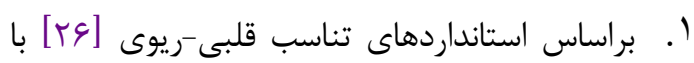
تعيين

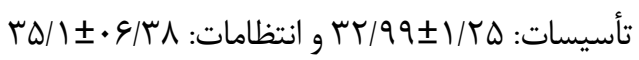

جدول ه. مقايسهُ PWC كاركنان با مقادير استانداردشده براى شغل آنها (برحسب MET)

\begin{tabular}{|c|c|c|c|c|c|c|}
\hline از موررنياز & $\begin{array}{c}\text { ميانَّن } \\
\text { PWC } \\
\text { افراد } \\
\text { (MET) }\end{array}$ & $\begin{array}{c}\text { ميانكَين افراد PWC } \\
\text { (Kcal/min) }\end{array}$ & $\begin{array}{c}\text { ميانَين (Kcal/min) } \\
\text { (معادل MET1) }\end{array}$ & انرزى موردنياز & نزديكترين كد شغلى & مشاغل \\
\hline$\cdot \pi \cdot$ & $f / v$. & $\Delta / 9 \Delta$ & $1 / 90$ & $\Delta / \cdot$ & IIAT. & خدمات \\
\hline$-\cdot / T T$ & r/VT & $\Delta / / F$ & $1 / 9 \Lambda$ & $r / \Delta$. & $111 \pi$. & نأسيسات \\
\hline$-1 / 49$ & $r / 99$ & $\Delta / \cdot F$ & $1 / 94$ & $r / Q$. & IIOTD & انتظامات \\
\hline
\end{tabular}

مردان نشاندهنده جاقى شكمى و مشكلات سلامتى در آينده

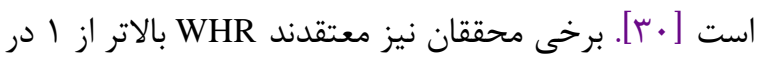

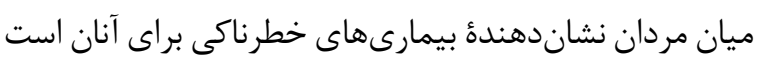

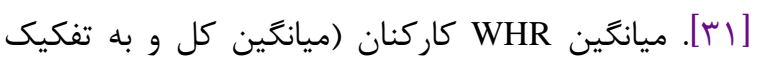
بخشها) پايينتر از نرخهاى مجاز توصيه شده بود. نرخ WHR

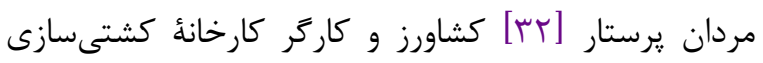
[سب] نيز مانند مطالعه حاضر در محدوده مجاز تشخيص داده

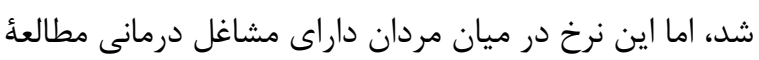
و Das توصيهشده WHO بود [عب]. دستعاه تحليلگر تركيبات بدن نشان مى دهد، در بيشتر تركيبات بدنى تفاوت معنادارى بين

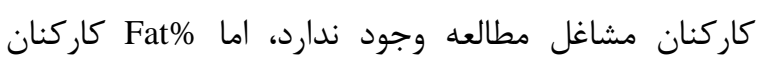
خدمات، بهطور معنادارى بيشتر از دو بخش شغلى ديخر بود.

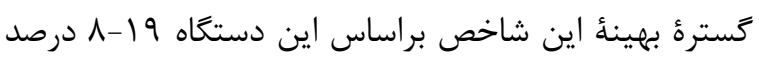

\section{بحث}

در اين مطالعه كه با هدف بررسى مشخصات فيزيولوزيك كاركنان بخش خدمات، تأسيسات و انتظامات يك سازمان كارى و تطابق آنها با مشاغلشان انجام شد، برخى مشخصات تاسيسات

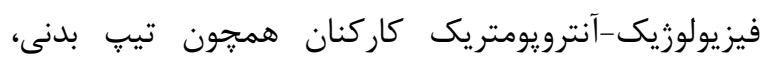
شاخص تودهُ بدنى و Fat\% نامناسب بود. آمادگى قلبى -عروقى شركت كنند ضعيف دستابندى شد. همجنين نتايج مطالعه نشاندهنده تناسبنداشتن كاركنان انتظامات و خدمات با مشاغلشان بود. شاخصى است كه با تقسيم محيط كمر به محيط

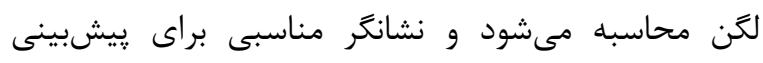

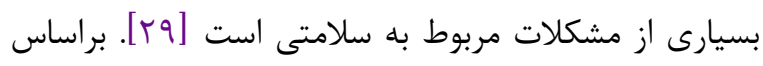

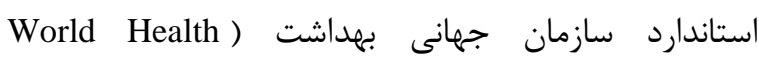

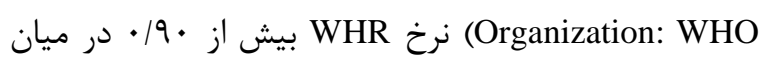




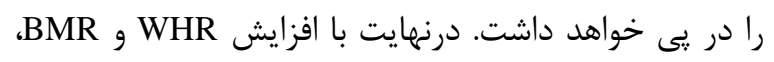
افزايش BMI نيز قابلتفسير خواهد بود. نتايج مشابهى در

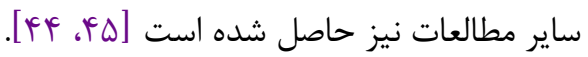

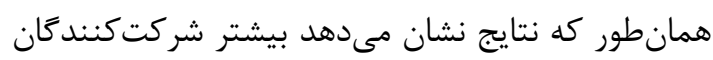
در مطالعه فعاليت فيزيكى شديدى داشتند كه سهرم كاركنان

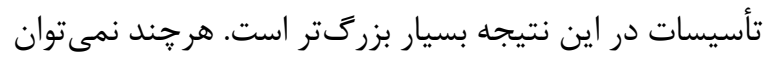
از كمبودن مشهود فعاليت فيزيكى در بين كاركنان انتظامات

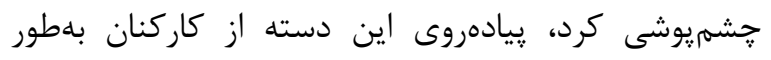

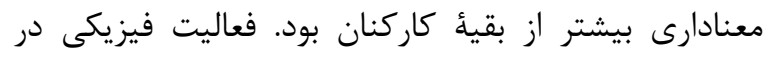

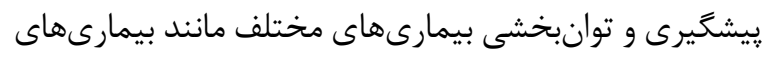

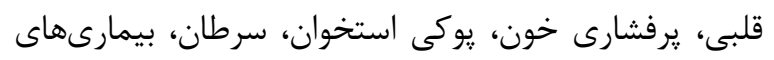

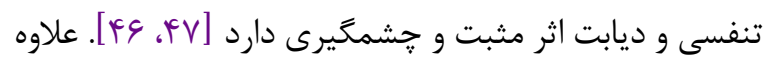

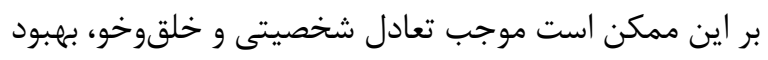

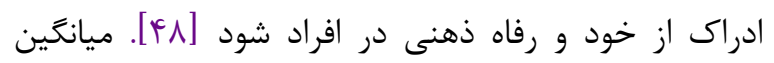

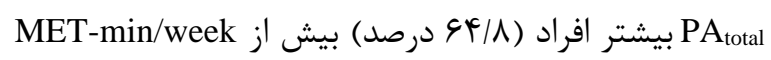

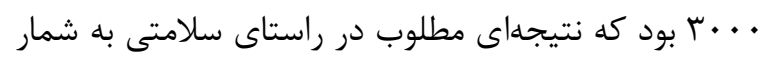

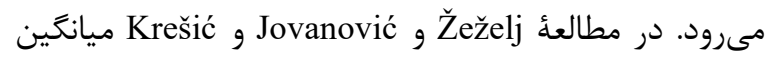

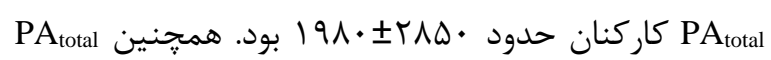

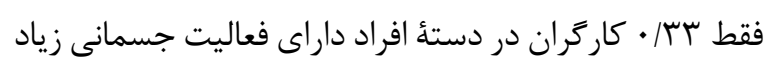

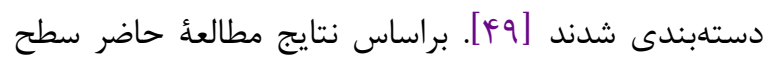

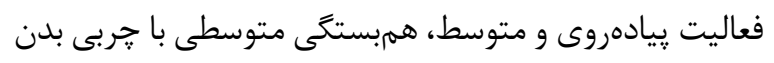

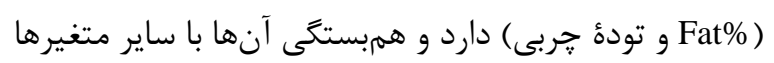

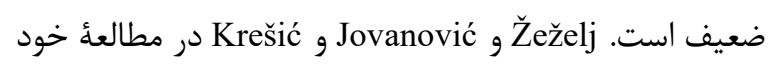
همبستخى معنادارى بين سطح فعاليت فيزيكى و جنسيت،

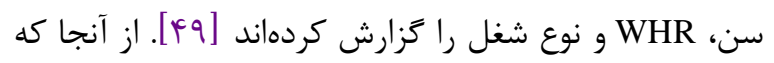

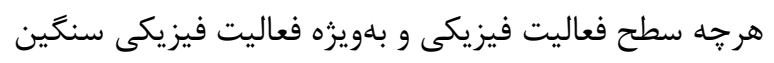

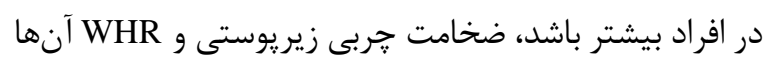

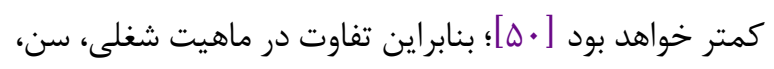
WHR و... مى تواند تفاوت PA

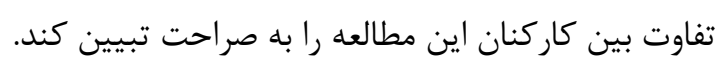

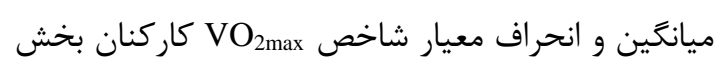

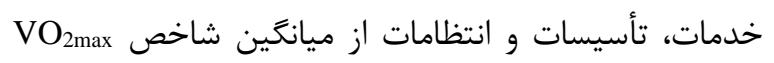

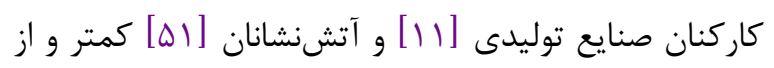

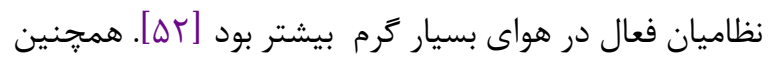

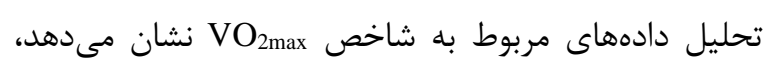

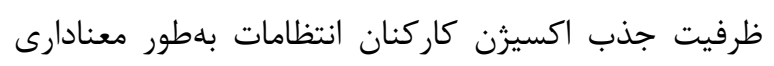

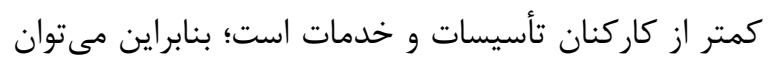

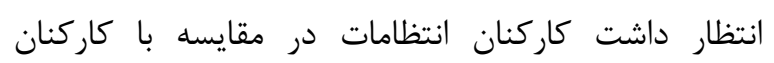

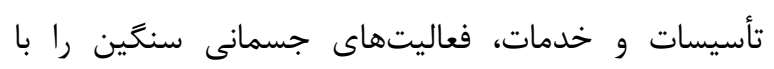

است كه اين كسترؤ بهينه در مطالعات مختلف، متفاوت است.

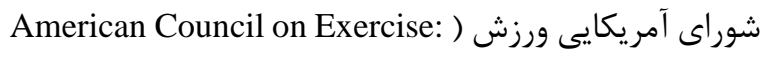
If-IV ميزان بهينة Fat\% براى مردان را كسترة (ACE

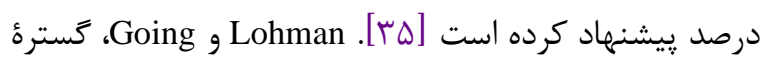

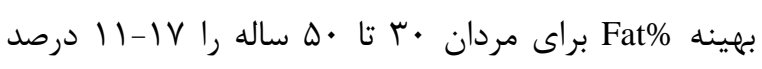

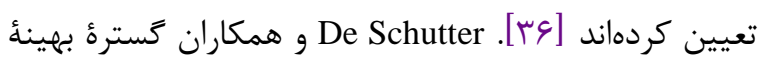

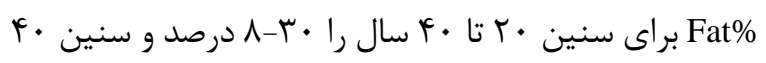

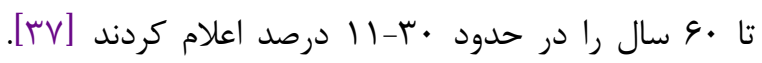

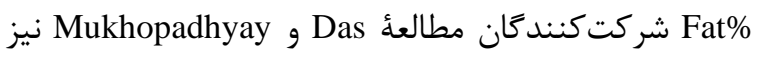

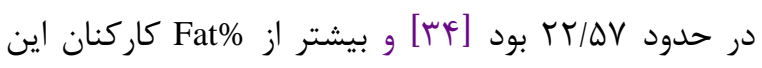

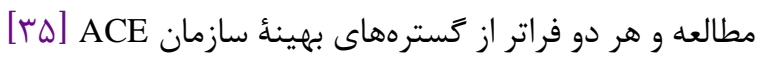

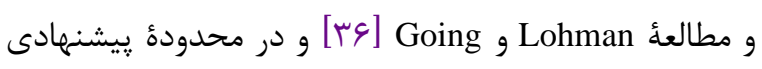
و و همكاران بودند [rVe Schutter

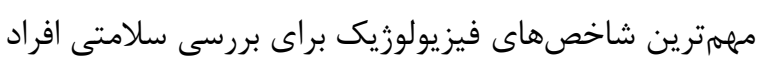

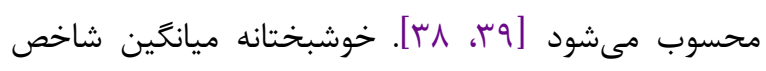

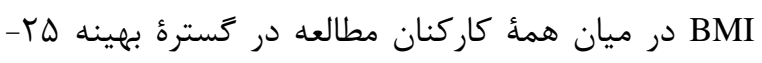

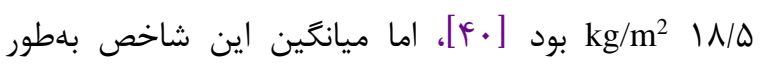
معنادارى در ميان كاركنان تأسيسات بيشتر از كاركنان إنان

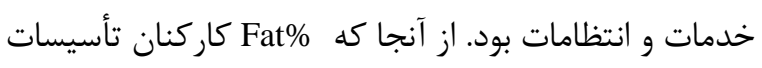
در كستره نرمال قرار داشت، بيشتربودن BMI اينظمات بود آنجات كاركنان

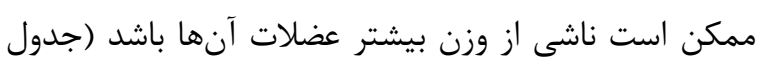

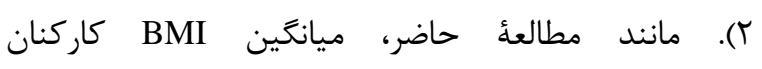

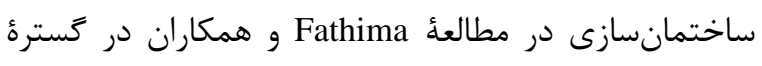

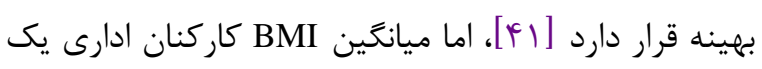

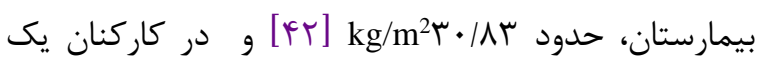

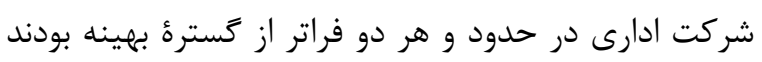

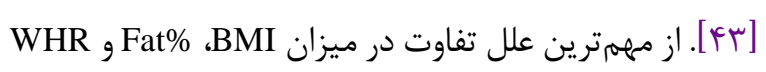

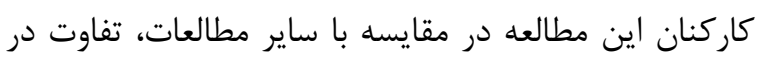

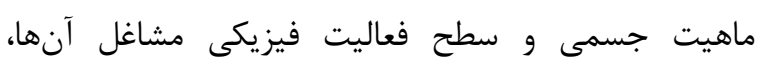
ويزگى هاى دموكرافيك و شرايط محيطى است.

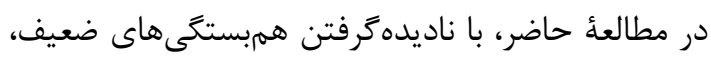

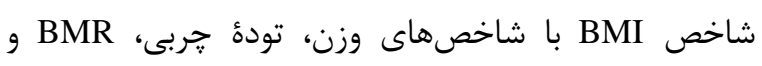

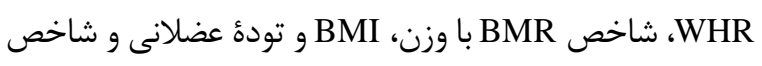

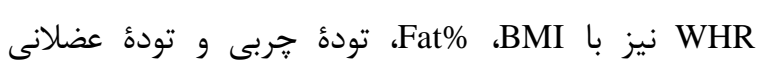

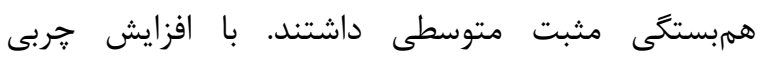

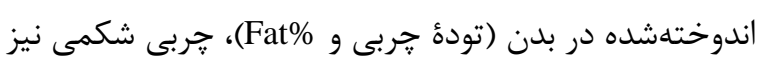

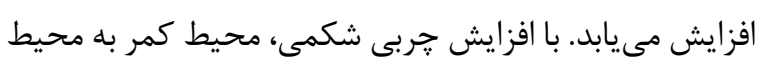

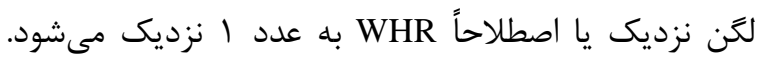

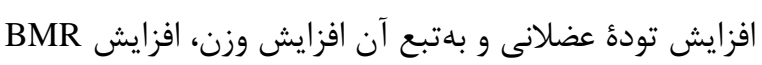




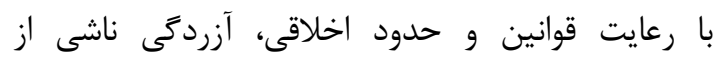

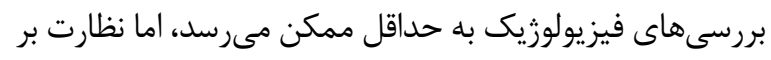

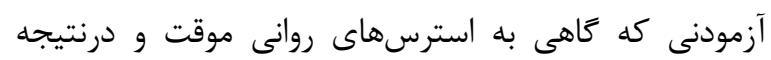

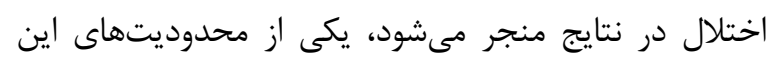

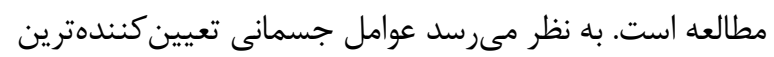

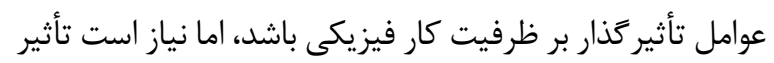

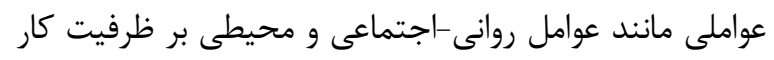

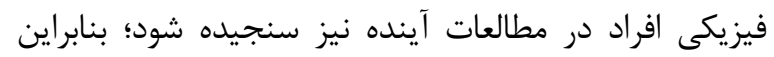

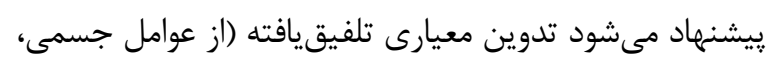

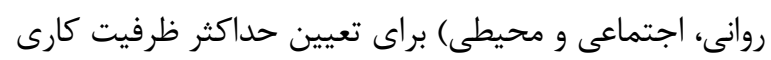
در مطالعات آتى مدنظر قرار گيرد.

\section{نتيجه $\bar{~}$}

برخى مشخصات فيزيولوزيك كاركنان، مانند تيب بدنى،

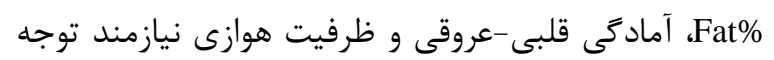

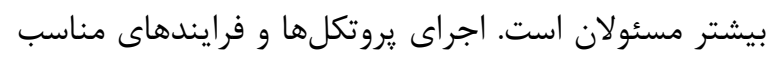

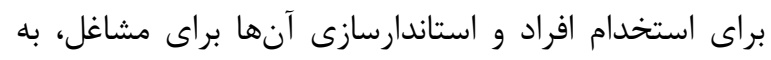

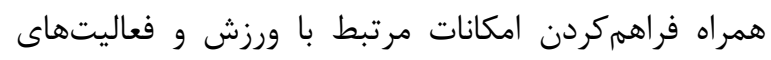

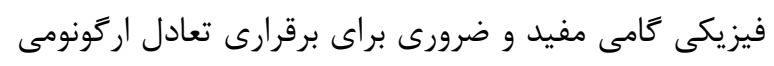

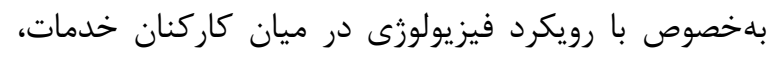
تأسيسات و انتظامات خواهد بودي فودرد

\section{تقدير و تشكر}

اين يزوهش در قالب طرح تحقيقات دانشجويى (شماره

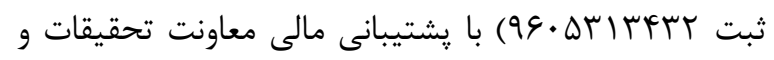

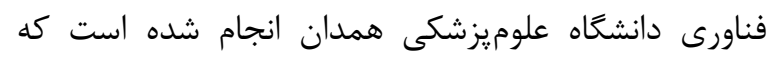
بدينوسيله نهايت تشكر و قدردانى به عمل مى هئ آيد.

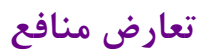

بين نويسندكان هيجَّونه تعارضى در منافع وجود ندارد.

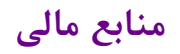

اين مطالعه با پشتيبانى مالى معاونت تحقيقات و فناورى مانى دانشخاه علوم يزشكى همدان انجام يافته است.

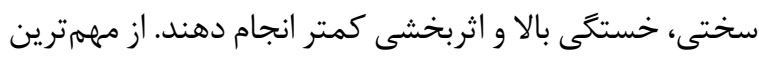

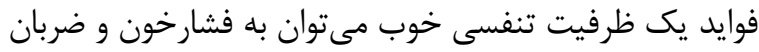

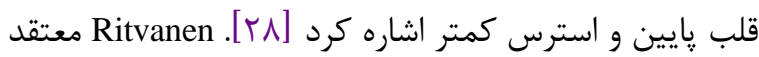

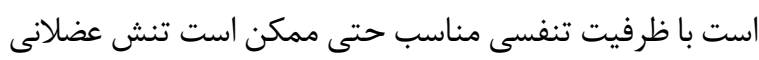

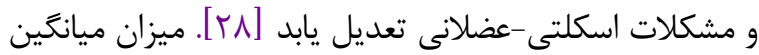

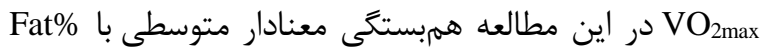

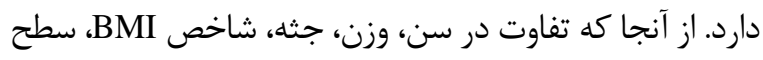
فعاليت فيزيكى، تركيبات بدن و... قابليت تأثير كذارى بر توان اندان

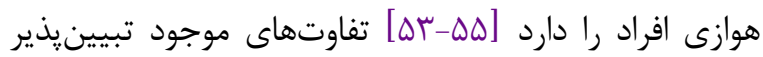

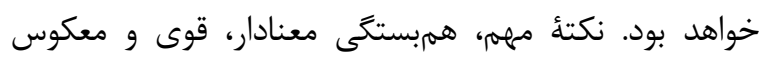
ضربان قلب با سابقه كار و سن افراد است؛ به اين معنا كه با باد

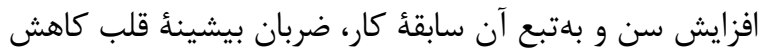

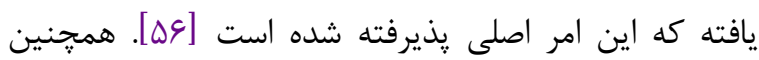

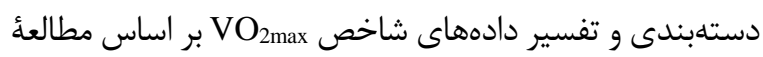
MacArdle سيستم قلبى -عروقى شركت كنند

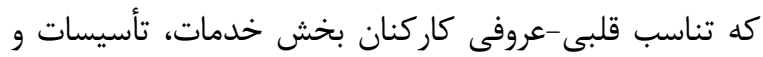

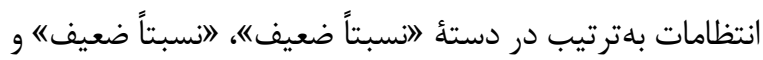
| (متوسط 《قرار ترفت.

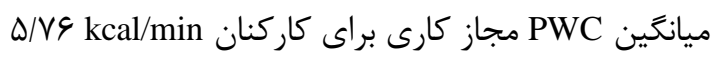

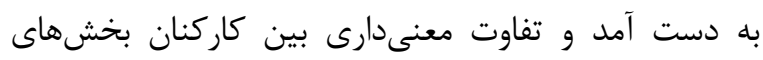

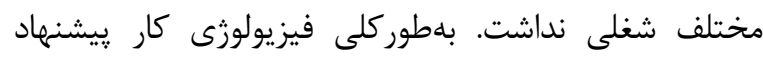
مى كند كار ييوسته در طول ^ ساعت، بايد بار كارى معادل

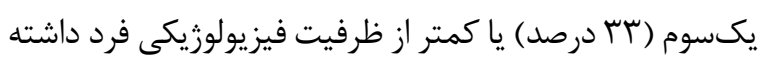

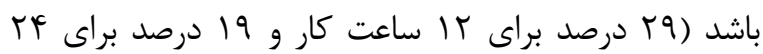

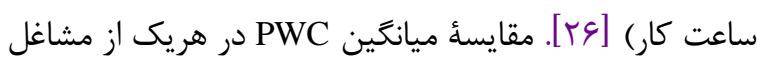

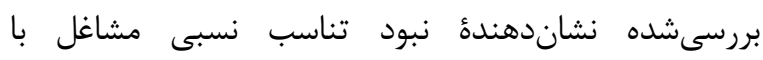

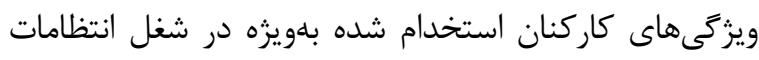

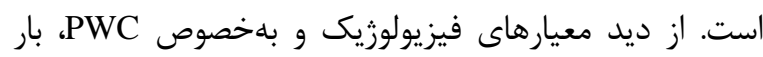

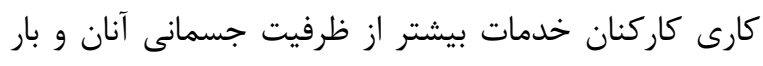

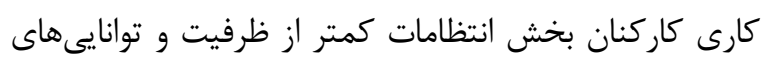

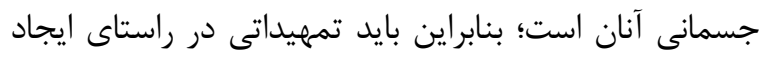

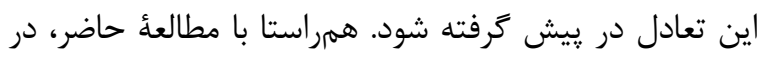

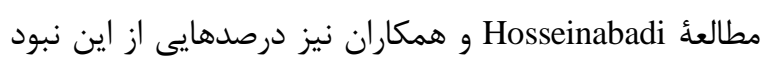

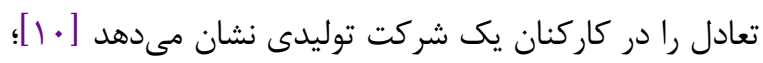

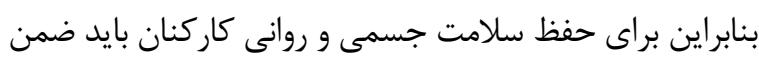

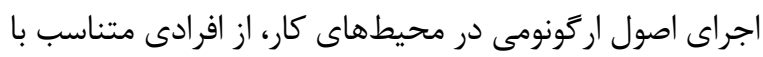
نيازمندى إى إى شغل استفاده شود. 


\section{References}

1. Grandjean E, Kroemer KH. Fitting the task to the human: a textbook of occupational ergonomics. CRC press; 1997 Jul 31. [DOI:10.1201/b16825] [PMCID]

2. Pheasant S, Haslegrave CM. Bodyspace: Anthropometry, ergonomics and the design of work. CRC press; 2005 Jul 18.

3. Miyake S, Yamada S, Shoji T, Takae Y, Kuge N, Yamamura T. Physiological responses to workload change. A test/retest examination. Applied ergonomics. 2009 Nov 1;40(6):987-96. [DOI:10.1016/j.apergo.2009.02.005] [PMID]

4. Pollard JP, Heberger JR, Dempsey PG. Development of a model to determine oxygen consumption when crawling. Transactions of Society for Mining, Metallurgy, and Exploration, Inc. 2015;338(1):441.

5. Moreira-Silva I, Santos R, Abreu S, Mota J. Associations between body mass index and musculoskeletal pain and related symptoms in different body regions among workers. Sage Open. 2013 Jun 5;3(2):2158244013491952. [DOI:10.1177/2158244013491952]

6. Atkinson K, Lowe S, Moore S. Human development, occupational structure and physical inactivity among 47 low and middle income countries. Preventive medicine reports. 2016 Jun 1;3:40-5. [DOI:10.1016/j.pmedr.2015.11.009] [PMID] [PMCID]

7. Ainsworth BE, Haskell WL, Leon AS, Jacobs Jr DR, Montoye HJ, Sallis JF, Paffenbarger Jr RS. Compendium of physical activities: classification of energy costs of human physical activities. Medicine and science in sports and exercise. 1993 Jan 1;25(1):71-80. [DOI:10.1249/00005768-19930100000011] [PMID]

8. Ainsworth BE, Haskell WL, Whitt MC, Irwin ML, Swartz AM, Strath SJ, O Brien WL, Bassett DR, Schmitz KH, Emplaincourt PO, Jacobs DR. Compendium of physical activities: an update of activity codes and MET intensities. Medicine and science in sports and exercise. 2000 Sep 1;32(9; SUPP/1):S498-504. [DOI:10.1097/00005768200009001-00009] [PMID]

9. Arghavani F, TEIMOURI G, Ebrahimi K, JAVANMARDI M, RAHMANI K. Estimation of Maximal Aerobic Capacity (VO2-max) and Study of its Associated Factors among Industrial Male Workers in Snandaj city/Kurdistan Province2013. J Torbate heydarie Univ Med Sci. 1393;5(2):34-41.

10. Hosseinabadi S, Hamidi Bp, Ebrahimi H, Barkhordari A, Raie Bt. Estimation Of Aerobic Capacity (Vo2Max) And Physical Work Capacity In Laborers.

11. Choobineh A, Barzideh M, Gholami T, Amiri R, Tabatabaei HR, ALMASI HA. Estimation of aerobic capacity (Vo2-max) and study of its associated factors among male workers of industrial factories in
Sepidan/Fars province, 2009.. Sci Med J. 2011;10(1):1-12.

12. Boyce RW, Boone EL, Cioci BW, Lee AH. Physical activity, weight gain and occupational health among call centre employees. Occupational Medicine. 2008 Jun 1;58(4):238-44. [DOI:10.1093/occmed/kqm135] [PMID]

13. Choi S, Shin G. Effects of the center of mass of a stick vacuum cleaner on the muscle activities of the upper extremity during floor vacuuming. Applied ergonomics. 2018 Jul 1;70:1-5. [DOI:10.1016/j.apergo.2018.02.001] [PMID]

14. Mengelkoch LJ, Clark K. Comparison of work rates, energy expenditure, and perceived exertion during a 1-h vacuuming task with a backpack vacuum cleaner and an upright vacuum cleaner. Applied ergonomics. 2006 Mar 1;37(2):159-65. [DOI:10.1016/j.apergo.2005.05.002] [PMID]

15. Mujunen T. Ergonomic lifting and transferring techniques for security guards working in Hoivapiiria practical guide.

16. Jasiulewicz-Kaczmarek M, Drozyner P. Social dimension of sustainable development-safety and ergonomics in maintenance activities. InInternational Conference on Universal Access in HumanComputer Interaction 2013 Jul 21 (pp. 175-184). Springer, Berlin, Heidelberg. [DOI:10.1007/978-3642-39188-0_19]

17. Afshari D, Angali KA, Ahangar AS, Pour SM, Amirmoezi S. Effects of anthropometric and demographic factors on physical work capacity of students of Ahvaz University of Medical Sciences. Journal of Occupational Hygiene Engineering Volume. $2018 \quad$ Jan 1;4(4):12-9. [DOI:10.21859/johe.4.4.12]

18. Aittasalo M, Miilunpalo S, Suni J. The effectiveness of physical activity counseling in a work-site setting: A randomized, controlled trial. Patient Education and Counseling. 2004 Nov 1;55(2):193-202. [DOI:10.1016/j.pec.2003.09.003] [PMID]

19. Craig CL, Marshall AL, Sjöström M, Bauman AE, Booth ML, Ainsworth BE, Pratt M, Ekelund UL, Yngve A, Sallis JF, Oja P. International physical activity questionnaire: 12-country reliability and validity. Medicine \& science in sports \& exercise. 2003 Aug 1;35(8):1381-95. [DOI:10.1249/01.MSS.0000078924.61453.FB] [PMID]

20. Deng H, Macfarlane D, Thomas G, Lao X, Jiang C, Cheng K, Lam T. Reliability and validity of the IPAQ-Chinese: the Guangzhou Biobank Cohort study. Medicine+ Science in Sports+ Exercise. 2008 Feb 1;40(2):303. [DOI:10.1249/mss.0b013e31815b0db5] [PMID]

21. Hagströmer $\mathrm{M}, \mathrm{Oja} \mathrm{P}, \mathrm{Sjöström} \mathrm{M}$. The International Physical Activity Questionnaire (IPAQ): a study of concurrent and construct validity. Public health 
ندا مهدوى و همكاران | بررسى تناسب فيزيولوزيك كاركنان تأسيسات، خدمات و انتظامات با مشاغل آنها

nutrition. $\quad 2006 \quad$ Sep;9(6):755-62. [DOI:10.1079/PHN2005898] [PMID]

22. Vasheghani-Farahani A, Tahmasbi M, Asheri H, Ashraf H, Nedjat S, Kordi R. The Persian, last 7-day, long form of the International Physical Activity Questionnaire: translation and validation study. Asian journal of sports medicine. 2011 Jun;2(2):106. [DOI:10.5812/asjsm.34781] [PMID] [PMCID]

23. Committee IR. Guidelines for data processing and analysis of the International Physical Activity Questionnaire (IPAQ)-short and long forms. http//www ipaq ki se/scoring pdf. 2005;

24. McARDLE WI, Katch F, Pechar G, Jacobson LO, Ruck S. Reliability and interrelationships between maximal oxygen intake, physical work capacity and step-test scores in college women. Medicine and science in sports. 1972 Dec;4(4):182-6. [DOI:10.1249/00005768-197200440-00019]

25. McArdle WD, Katch FI, Katch VL. Exercise physiology: nutrition, energy, and human performance. Lippincott Williams \& Wilkins; 2010.

26. Bink B. The physical working capacity in relation to working time and age. Ergonomics. 1962 Jan 1;5(1):25-8. [DOI:10.1080/00140136208930548]

27. Kumahara $H$, YOSKIOKA $M$, Yoshitake $Y$, SHINDO M, SCHUTZ Y, TANAKA H. The difference between the basal metabolic rate and the sleeping metabolic rate in Japanese. Journal of nutritional science and vitaminology. 2004;50(6):441-5. [DOI:10.3177/jnsv.50.441] [PMID]

28. Ritvanen $\mathrm{T}$, Louhevaara $\mathrm{V}$, Helin $\mathrm{P}$, Halonen $\mathrm{T}$, Hänninen $\mathrm{O}$. Effect of aerobic fitness on the physiological stress responses at work. International journal of occupational medicine and environmental health. 2007 Jan 1;20(1):1-8.2007;20(1):1-8. [DOI:10.2478/v10001-007-0005-5] [PMID]

29. Anusruti A, Jansen EH, Gào X, Xuan Y, Brenner H, Schöttker B. Longitudinal associations of body mass index, waist circumference, and Waist-to-Hip ratio with biomarkers of oxidative stress in older adults: results of a large cohort study. Obesity Facts. 2020;13(1):66-76. [PMID] [PMCID]

[DOI:10.1159/000504711]

30. Molarius A, Seidell JC, Sans S, Tuomilehto J, Kuulasmaa K. Waist and hip circumferences, and waist-hip ratio in 19 populations of the WHO MONICA Project. International journal of obesity. 1999 [DOI:10.1038/sj.ijo.0800772] [PMID]

Feb;23(2):116-25.

31. Hajian-Tilaki K. Receiver operating characteristic (ROC) curve analysis for medical diagnostic test evaluation. Caspian journal of internal medicine. 2013;4(2):627.

32. Ramin CA, Massa J, Wegrzyn LR, Brown SB, PierrePaul J, Devore EE, Hankinson SE, Schernhammer ES. The association of body size in early to mid-life with adult urinary 6-sulfatoxymelatonin levels among night shift health care workers. BMC Public Health.
2015 Dec 1;15(1):467. [DOI:10.1186/s12889-0151770-x] [PMID] [PMCID]

33. Folsom AR, Li Y, Rao X, Cen R, Zhang K, Liu X, He L, Irving S, Dennis BH. Body mass, fat distribution and cardiovascular risk factors in a lean population of south China. Journal of clinical epidemiology. 1994 Feb 1;47(2):173-81. [DOI:10.1016/08954356(94)90022-1]

34. Das SK, Mukhopadhyay S. Effect of altered body composition on musculoskeletal disorders in medical practitioners. Int J Res Eng Tech. 2016;5.

35. Muth ND, Zive MM. Sports nutrition for health professionals. FA Davis; 2019 Sep 4.

36. Lohman TG, Going SB. Multicomponent models in body composition research: opportunities and pitfalls. InHuman body composition 1993 (pp. 53-58). Springer, Boston, MA. [DOI:10.1007/978-1-48991268-8_10] [PMID]

37. De Schutter A, Lavie CJ, Patel DA, Artham SM, Milani RV. Relation of body fat categories by Gallagher classification and by continuous variables to mortality in patients with coronary heart disease. The American journal of cardiology. 2013 Mar 1;111(5):657-60. [DOI:10.1016/j.amjcard.2012.11.013] [PMID]

38. Harrison S, Tilling K, Turner EL, Martin RM, Lennon R, Lane JA, Donovan JL, Hamdy FC, Neal DE, Bosch JR, Jones HE. Systematic review and metaanalysis of the associations between body mass index, prostate cancer, advanced prostate cancer, and prostate-specific antigen. Cancer Causes \& Control. 2020 Mar 11:1-9. [DOI:10.1101/19005421]

39. Heslehurst N, Vieira R, Akhter Z, Bailey H, Slack E, Ngongalah L, Pemu A, Rankin J. The association between maternal body mass index and child obesity: A systematic review and meta-analysis. PLoS medicine. 2019 Jun 11;16(6):e1002817. [DOI:10.1371/journal.pmed.1002817] [PMID] [PMCID]

40. Status WP. The use and interpretation of anthropometry. WHO technical report series. 1995;854(9).

41. Fathima AV, Dutt AR, Bhat SK, Bhat B, Fakruddin AV. A comparative study of handgrip strength among sedentary and non-sedentary workers. National Journal of Physiology, Pharmacy and Pharmacology. 2017;7(3):265-8. [DOI:10.5455/njppp.2017.7.0927706102016]

42. John J, Swartz MD, Hoelscher D, Huber C, Sharma S. Measures of Physical Activity and Body Mass Index in Hospital Workers: A Multisite CrossSectional Study. Journal of occupational and environmental medicine. 2019 May 1;61(5):e176-82. [DOI:10.1097/JOM.0000000000001561] [PMID]

43. Shariat A, Cardoso JR, Cleland JA, Danaee M, Ansari NN, Kargarfard M, Mohd Tamrin SB. Prevalence rate of neck, shoulder and lower back pain in association with age, body mass index and gender among Malaysian office workers. Work. 2018 Jan 
44. Donma O, Donma MM. Evaluation of the weightbased and fat-based indices in relation to basal metabolic rate-to-weight ratio. International Journal of Medical and Health Sciences. 2019 Apr 3;13(5):214-8.

45. Kim DH, So WY. Relationship of basal metabolic rate with age, body mass index, waist circumference, fat mass, and fat-free mass in African American college students. HealthMED. 2013:889.

46. Caldwell JR. Exercise in the elderly: An overview. Activities, Adaptation \& Aging. 1996 Apr 9;20(3):38. [DOI:10.1300/J016v20n03_02]

47. Elrick H. Exercise is medicine. The Physician and Sportsmedicine. 1996 Feb 1;24(2):72-8 [DOI:10.1080/00913847.1996.11947914] [PMID]

48. Chung YB, Baird MK. Physical exericse as a counseling intervention. Journal of Mental Health Counseling. 1999 Apr 1;21(2):124.

49. Žeželj SP, Jovanović GK, Krešić G. The association between the Mediterranean diet and high physical activity among the working population in Croatia. Medycyna pracy. 2019 Apr 19;70(2):169-76. [DOI:10.13075/mp.5893.00773] [PMID]

50. Tremblay A, Després JP, Leblanc C, Craig CL, Ferris B, Stephens T, Bouchard C. Effect of intensity of physical activity on body fatness and fat distribution. The American journal of clinical nutrition. $1990 \mathrm{Feb}$ 1;51(2):153-7. [DOI:10.1093/ajcn/51.2.153] [PMID]

51. Firoozeh M, Saremi M, Maleki A, Kavousi A. Investigation of maximal aerobic capacity and associated factors in firefighters. Iran Occupational Health. 2015 Aug 10;12(3):15-26.

52. Valipour F, Khavanin A, Asiliyan H, Mohebi HA, Jonaidi N. Measurement of Physical Work Capacity (PWC) for Iranian Military Personnel in Different Condition Chamber Laboratory Clime (Normal and Very Heat Humid). Journal Mil Med. 2007 Apr 10;9(1):67-72.

53. Daneshmandi H, Fard AR, Choobineh A. Estimation of aerobic capacity and determination of its associated factors among male workers of industrial sector of Iran. International journal of occupational safety and ergonomics. 2013 Jan 1;19(4):667-73. [DOI:10.1080/10803548.2013.11077014] [PMID]

54. Hosseini S, Ravandi MR, Khanjani N. Estimating Aerobic Capacity (VO2-max) Using a Single-stage Step Test and Determining its Effective Factors. International Journal of Occupational Hygiene. 2017 Nov 18;9(4):201-6.

55. Lyons J, Allsopp A, Bilzon J. Influences of body composition upon the relative metabolic and cardiovascular demands of load-carriage. Occupational medicine. 2005 Aug 1;55(5):380-4. [DOI:10.1093/occmed/kqi087] [PMID]

56. Londeree BR, Moeschberger ML. Effect of age and other factors on maximal heart rate. Research quarterly for exercise and sport. 1982 Dec 